\title{
High-sensitivity radiation detector for low dose level radiological applications
}

\author{
Mauro Valente ${ }^{* \dagger}$ \\ Institute of Physics E. Gaviola - CONICET, Córdoba; Argentina \\ LIF AMIR ${ }^{X}$ - Laboratorio de Investigación e Instrumentación en Física Aplicada a la \\ Medicina e Imágenes por Rayos X - University of Córdoba; Argentina \\ E-mail: valentedfamaf.unc.edu.ar

\section{Wladimir Molina} \\ LIF AMIR ${ }^{X}$ - Laboratorio de Investigación e Instrumentación en Física Aplicada a la \\ Medicina e Imágenes por Rayos X - University of Córdoba; Argentina \\ Instituto Venezolano de Investigaciones Científicas, Caracas; Venezuela \\ E-mail: wmolina@ivic.gob.ve

\section{José Vedelago} \\ Institute of Physics E. Gaviola - CONICET, Córdoba; Argentina \\ LIFAMIR ${ }^{X}$ - Laboratorio de Investigación e Instrumentación en Física Aplicada a la \\ Medicina e Imágenes por Rayos X - University of Córdoba; Argentina \\ E-mail: jvedelago@famaf.unc.edu.ar
}

\begin{abstract}
Radiation dosimetry by Fricke gel was largely used, generally focused and optimized for radiotherapy applications therefore involving relative high dose levels. Fricke gel dosimetry has several advantages, like dose rate and LET almost independence, 3D mapping, among other. This work presents a novel Fricke gel dosimeter optimized for low dose levels. Several chemical composition were studied varying concentrations of sulfuric acid $\left(\mathrm{H}_{2} \mathrm{SO}_{4}\right)$, ferrous ammonium sulphate $\left(\left(\mathrm{NH}_{4}\right)_{2} \mathrm{Fe}\left(\mathrm{SO}_{4}\right)_{2} \cdot 6 \mathrm{H}_{2} \mathrm{O}\right)$, benzoic acid $\left(\mathrm{C}_{7} \mathrm{H}_{6} \mathrm{O}_{2}\right)$ and Xylenol orange $\left(\mathrm{C}_{31} \mathrm{H}_{32} \mathrm{~N}_{2} \mathrm{O}_{13} \mathrm{~S}\right)$. Samples were analyzed by light transmission and absorbance. Sensitivity for low dose levels was significantly improved testing typical radiology setups. Comparisons with ionization chamber showed good agreement. Thus, remarking reliability of the developed system as promising tool for low-level dosimetry.
\end{abstract}

X Latin American Symposium on Nuclear Physics and Applications (X LASNPA),

1-6 December 2013

Montevideo, Uruguay

\footnotetext{
* Speaker.

${ }^{\dagger}$ www.famaf.unc.edu.ar/ valente
} 


\section{INTRODUCTION}

Ionizing radiation is daily used for therapeutic and diagnostic medical procedures. Then, it has to be considered the effects and risks of radiation exposure. Actually, reliable dosimetry in medical practices has to be carefully investigated [1][2].

Fricke gel dosimetry (FGD) [3][4][5] has a lot of advantages, mainly 3D continuous mapping [5], tissue-equivalence and beam quality independence [6][7][8].

The present study presented briefly a novel Fricke gel dosimeter with high sensitive at low dose levels. Several chemical compositions were studied for performance improving [6][9][10]. Comparisons with conventional dosimetry indicated feasibility and reliability [2][10]. As preliminary application in clinics, it was used a computed tomography (CT) configuration.

\section{MATERIALS AND METHODS}

A conventional X-ray tube was used as radiation source providing wide range of variations of both current and voltage for configuring different beam qualities.

Fricke gel dosimeters were prepared in standard vials and optically analyzed by spectrophotometry (UNICO 1205 Vis equipment), using samples of ultra pure (tridistilled) water UV quartz vials as absorbance reference pattern. A calibrated ionization chamber (PTW TN 30013) was used as reference for dosimetry. Phantoms with certain properties allowed insertion of both Fricke gel vials and ionization chamber.

The composition used as starting point [10] consisted of $124.38 \mathrm{mM}$ porcine skin gel, 0.6 $\mathrm{mM}$ ferrous ammonium sulphate, $8 \mathrm{mM}$ sulfuric acid, $2 \mathrm{mM}$ Xylenol orange and $96 \%$ ultra pure water. Chemical compositions was modified varying the components one at the time characterizing sensitivity and stability. Dose-response linearity and reproducibility were studied by several experiments using different chemical compositions and solution batches [11].

An adapted Computed Tomography (CT) facility was used for evaluating the performance in radiology. There were separated some samples from each elaboration batch to be used for calibration curves measurements. A linear regression model was applied for dose-response characterization. Finally, absorbed dose comparisons were accomplished traducing both FGD and ionization chamber read outs to dose in water.

\section{RESULTS AND DISCUSSIONS}

There were performed a large quantity of tests varying chemical composition attempting to evaluate optimal concentration of each component. As example of the obtained results for component variations Figure 1 shows the effect of $\mathrm{H}_{2} \mathrm{SO}_{4}, \mathrm{FeSO}_{4}$.

Similarly was studied the effect of varying the concentration of all other components as well as the addition of $5 \mathrm{mM}$ of benzoic acid improving stability and sensitivity. Finally, the composition considered as the optimal one [11], called Benzoic Fricke Gel Dosimeter (BFGD), consisted of: 5 $\mathrm{mM} \mathrm{C}_{7} \mathrm{H}_{6} \mathrm{O}_{2}, 29 \mathrm{mM} \mathrm{H}_{2} \mathrm{SO}_{4}, 0.3 \mathrm{mM}\left(\mathrm{NH}_{4}\right)_{2} \mathrm{Fe}\left(\mathrm{SO}_{4}\right)_{2} \cdot 6 \mathrm{H}_{2} \mathrm{O}$ and $0.1 \mathrm{mM}$ Xylenol orange in a gel matrix of $124.38 \mathrm{mM}$ with $96 \%$ of volume with ultra pure water. 

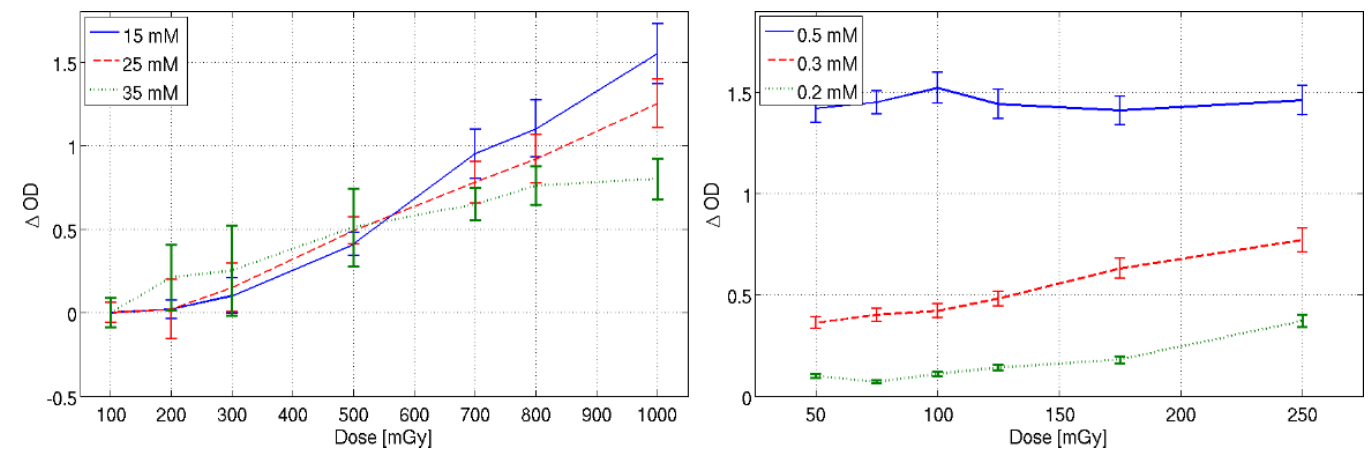

Figure 1: FGD dose-response modifying $\mathrm{H}_{2} \mathrm{SO}_{4}$ (left) and $\mathrm{FeSO}_{4}$ (right) concentrations.
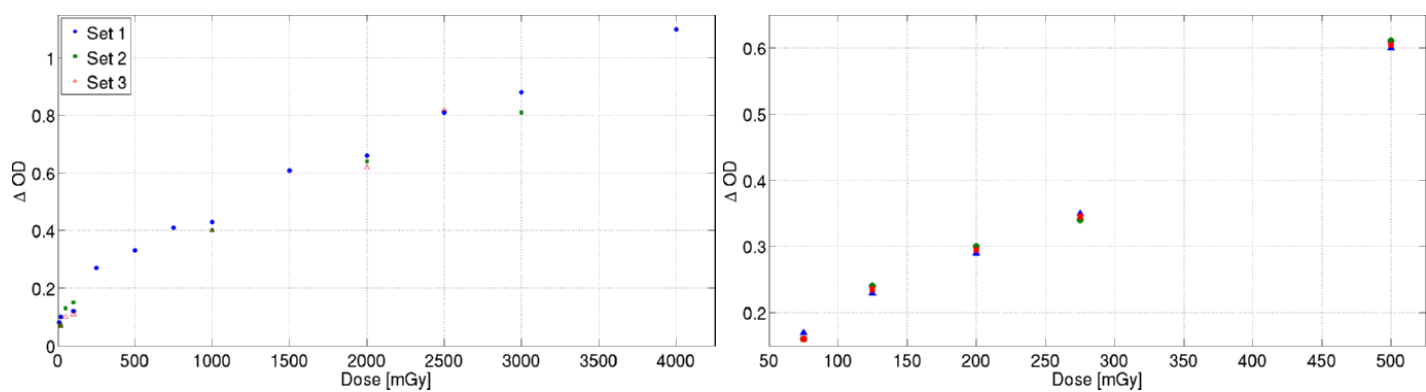

Figure 2: Dose-response reproducibility (left) and beam quality dependence (right).

Dose-response linear trend and reproducibility along with beam quality dependence were studied for different solution batches. The obtained results are shown in Figure 2.

Then, it was investigated dose-response for different beam qualities corresponding to typical radiological practices.

Dedicated experiments highlighted the performance of the developed system for clinical-like applications. After that Fricke gel samples were placed at measuring location inside cylindrical water-filled acrylic phantoms and tomography scanning was carried out according to irradiation the set up sketched in Figure 3.
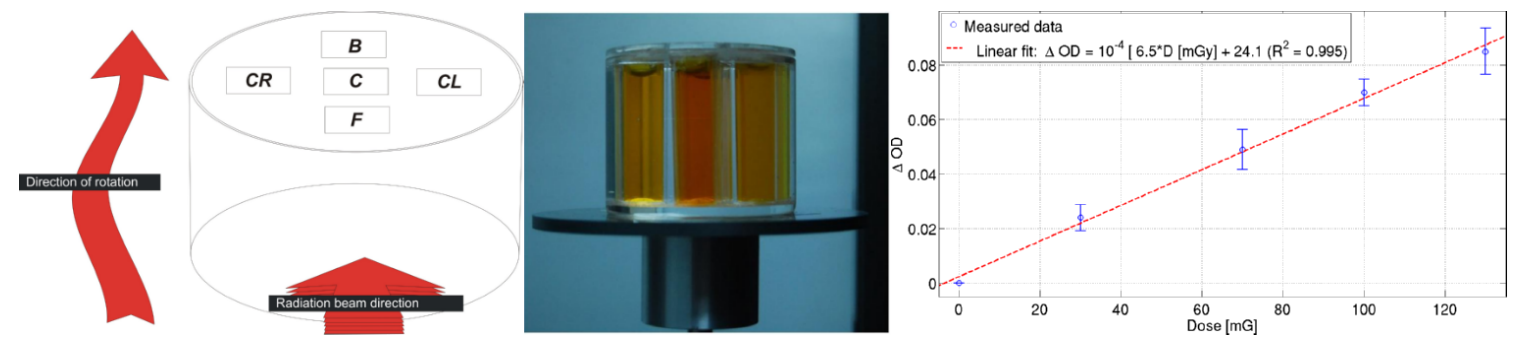

Figure 3: Tomography scanning set up for irradiation of Fricke gel samples indicating center (C), front (F), bottom (B), left (CL) and right (CR) sample positions (detector perspective).

The calibration curve obtained for tomography scanning is also shown in Figure 3, obtaining a linear correlation coefficient of $R^{2}=0.99$, then absorbed dose was directly assessed for the whole CT scanning measuring at the indicated location inside water-equivalent phantoms. The obtained results are reported in Table 1. 


\begin{tabular}{|c|cc|}
\hline Vial Location & Fricke Dosimeter & Ionizing Chamber \\
\hline Rigth (CR) & $(102.3 \pm 3.1)$ & $(100.1 \pm 0.1)$ \\
\hline Left (CL) & $(121.0 \pm 4.5)$ & $(123.7 \pm 0.2)$ \\
\hline Center (C) & $(131.0 \pm 3.1)$ & $(134.0 \pm 0.1)$ \\
\hline Front (F) & $(74.5 \pm 8.2)$ & $(78.6 \pm 0.1)$ \\
\hline Bottom (B) & $(94.2 \pm 6.4)$ & $(100.6 \pm 0.2)$ \\
\hline
\end{tabular}

Table 1: Estimation of absorbed dose (in mGy) with Benzoic Fricke gel dosimeter and ionization chamber for $\mu \mathrm{CT}$ scanning.

\section{CONCLUSIONS}

According to the obtained results, it can be stated that the novel Fricke gel dosimetry system developed for low dose level applicaions proved to exhibit the desired linear response and as well as high sensitivity in the range of 50 to $3000 \mathrm{mGy}$, at least. Actually, it was shown that dose response values were well distinguishable from the background. Furthermore, as quantitative dosimetry system its performance was similar to conventional dosimetry system.

Finally, as general comments it might be remarked that the developed dosimetry system attained surely high dose sensitivity enough to be considered as a potential useful tool for radiology quality assurance.

\section{Acknowledgments}

This work was partially supported by ISIDORA I of SeCyT-UNC and PIP 11420090100398 of CONICET projects; Argentina.

\section{References}

[1] B. Paliwal and D. Tewatia. Advances in radiation therapy dosimetry. J Med Phys. 34 (3), pp. 108-116, 2009.

[2] L. Schreiner. Review of Fricke gel dosimeters. Jour. Phys. Conf. Ser. 3 pp. 9-21, 2004.

[3] H. Fricke and S. Morse. The chemical action of Roentgen rays on dilute ferrosulphate solutions as a measure of dose. Am. J Roent. Radium Ther. Nucl. Med. 18 pp. 430-432, 1927.

[4] H. Fricke and E. Hart. Chemical Dosimetry In: Radiation Dosimetry vol. 2, Ed. F. Attix and W. Roesch. Academic Press New York, 1955.

[5] L. Olsson, A. Appleby I. Sommer. A new dosimeter based on ferrous sulphate solution and agarose gel. Appl. Radiat. Isot. 42 pp. 1081-1086, 1991.

[6] M. Valente, G. Bartesaghi, G. Gambarini, D. Brusa, G. Castellano, M. Carrera. Fricke gel Dosimeter Tissue Equivalence: a Monte Carlo Study. Proceedings of Astroparticles, Particles and Space Physics, Detectors and Medical Physics and Applications. pp. 605-609, 2007.

[7] M. Mariani, E. Vanosi, G. Gambarini, M. Carrara, M. Valente. Preliminary results from polymer gel dosimeter for absorbed dose imaging in radiotherapy Rad. Phys. Chem. 76(8) pp. 1507-1513, 2007. 
[8] E. Vanosi, M. Carrara M, G. Gambarini, M. Mariani, M. Valente. Study of polymer gel for dose imaging in radiotherapy Rad Meas. 43(2) pp. 442-446, 2008.

[9] M. Carrara, G. Gambarini, S. Tomatis, M. Valente. Dose distribution measurements by means of gel-layer dosimeters. Evaluation of algorithms for artefacts amendment Nuc. Inst. Meth. Phys. 579 pp. 334-338, 2007.

[10] M. Valente. Fricke gel dosimetry for 3D imaging of absorbed dose in radiotherapy $\mathrm{PhD}$. thesis, University of Milan, Italy, 2007.

[11] W. Molina. Desarrollo y caracterización de un sistema de Fricke gel para dosimetría en radiodiagnóstico MSc. thesis, Instituto Venezolano de Investigaciones Científicas, Rep. Bolivariana de Venezuela, 2013. 